\title{
The influence of the heat and power system on the comfort of the living environment
}

\author{
A STUPINA ${ }^{1,3,6}$, M POKUSHKO $^{1,3,4}$, O SHAGAEVA $^{5}$, I MEDINA-BULO $^{4}$, E DRESVIANSKII $^{2,4,3}, \mathrm{R}^{2}$ \\ $\mathrm{KUZMICH}^{1}$, O ANTAMOSKIN ${ }^{5,6,7,8}$, M TSEPKOVA ${ }^{1,9}$ \\ ${ }^{1}$ Institute of Business Process Management \\ University Siberian Federal University \\ 660041, Krasnoyarsk, Svobodny Ave., 79 \\ RUSSIA \\ ${ }^{2}$ Polytechnic Institute \\ University Siberian Federal University \\ 660041, Krasnoyarsk, Svobodny Ave., 79 \\ RUSSIA \\ ${ }^{3}$ Institute of Informatics and Telecommunications \\ Reshetnev Siberian State University of Science and Technology \\ 660037, Krasnoyarsk, Krasnoyarskii rabochii Ave, 31 \\ RUSSIA \\ ${ }^{4}$ Superior Engineering School \\ University of Cadiz \\ 11519, Puerto Real (Cadiz), University of Cadiz Ave., 10 \\ SPAIN \\ ${ }^{5}$ Institute for the Humanities \\ University Siberian Federal University \\ 660041, Krasnoyarsk, Svobodny Ave., 79 \\ RUSSIA \\ ${ }^{6}$ Economics and AIC administration \\ Krasnoyarsk State Agrarian University \\ 660049, Krasnoyarsk, Mira Avenue, 90 \\ RUSSIA \\ ${ }^{7}$ Institute of space and information technologies \\ University Siberian Federal University \\ 660041, Krasnoyarsk, Svobodny Ave., 79 \\ RUSSIA \\ ${ }^{8}$ Institute of Engineering and Economics \\ Reshetnev Siberian State University of Science and Technology \\ 660037, Krasnoyarsk, Krasnoyarskii rabochii Ave, 31 \\ RUSSIA \\ ${ }^{9}$ Krasnoyarsk Branch Saint-Petersburg University of the Humanities and Social Sciences \\ Saint-Petersburg University of the Humanities and Social Sciences \\ 660022, Krasnoyarsk, Aerovokzalnaya Ave, 4V \\ RUSSIA
}

\begin{abstract}
The study of the factors for the influence of the centralized municipal heat supply system on the comfort of the living environment. A technique is described that helps optimizing the positive effect of the heat and power system on the comfort of the living environment. This technique is based on the Data Envelopment Analysis (DEA) method. The article describes the method, considers the basic model used in the study. In accordance with the task set in the study, the indicators for the objects of the heat and power system were optimized to improve the comfort of the living environment. The Decision-Making Unit (DMU) inputs and outputs are determined, and a suitable DEA model for solving this problem is determined. heat and power plants and boiler houses of the region with a particularly severe and cold climate were selected as the studied DMUs.
\end{abstract}


The DEA model made it possible to adjust the performance of urban heat and power plants and boiler houses in such a way as to increase the comfort of the urban living environment. The approbation was carried out on specific indicators for the objects of the centralized municipal heat supply system in the city of Krasnoyarsk. Twelve DMUs from boiler houses and heat and power plants were analyzed. A calculation was carried out to optimize the performance of DMU data to improve the comfort of the living environment in the city of Krasnoyarsk. As a result of the study, it was revealed that seven objects of the system work in an optimal mode. Five objects of the system are not working in an optimal mode. Accordingly, these five objects revealed deviations in performance indicators from the recommended optimal values for solving the task set in the study. For these five objects, the performance indicators were adjusted in the optimal mode when solving the problem of improving the comfort of the living environment. That will contribute to improving the environmental situation in the city, especially in residential areas. This technique was applied to optimize the influence of the centralized municipal heat supply system on the comfort of the residential environment in the city of Krasnoyarsk. And it can be used in the future to solve this kind of problems. It is assumed that this technique can be applied to other regions with particularly severe and cold climates. The results of this study will be applied to the development of an automated geoinformation system, as well as an expert system of residential complexes in the city of Krasnoyarsk.

Key-Words: - heat and power system, centralized municipal heat supply system, housing and communal sector, comfort of the living environment, methodology, the Data Envelopment Analysis method, heat comfort, heat and power plants, mass of emissions.

Received: May 18, 2021. Revised: November 22, 2021. Accepted: December 18, 2021. Published: December 30, 2021.

\section{Introduction}

The development of the global fuel and energy complex largely depends on the state of the heat economy and the possibility of creating comfortable operating conditions for consumers. This is especially important for regions with a severe and cold climate. Moreover, the life support of such areas requires a high level of preparation and functioning of the heat and power system for residential and industrial complexes.

The increasing electricity demand every year has a stimulating effect on the development of heat and power systems. Power engineers worldwide are working towards improving heat and power plants, increasing their reliability, environmental safety, and efficiency. Heating takes a significant place in the energy complex of many countries. Heating is understood as the process of consumers centralized provision with heat energy obtained at heat and power plants using a combined method of generating heat and electric energy [1].

The peculiarity of the modern heat grid is its high social role-ensuring the vital activity of the country population. Therefore, for the Nordic countries, highquality heating of territories becomes an essential social task and has a high impact on the comfort of the living environment. The existing heating system of multi-stored residential buildings is organized as a central heating system. The central heating system is understood as the heat grid of consumers from heat sources through a common heating grid [2]. The housing and communal sector consumes a significant amount of heat for technological needs and heating, ventilation, and hot water supply. Depending on many factors, such as the location of the housing complex, capacity, the presence or absence of centralized heat supply system enterprises, and other factors, the heat and power system for such a complex can be of varying degrees of complexity. However, in any case, improving the reliability, safety, and efficiency of heat and power systems and equipment is one of the most important economic tasks for such housing complexes [3].

On the other hand, massive amounts of harmful emissions are emitted into the atmosphere during the operation of urban heat and power plants, boiler houses of heat, and power systems to provide heat to housing and communal services. In this regard, for many northern regions with a high development of industrial and housing infrastructure, there is a negative environmental situation. This factor has a huge impact on the comfort indicators of the living environment. Furthermore, many urban heat and power plants and boiler houses are located within the city limits and pollute the surrounding areas with residential buildings to a greater extent. The transfer of such enterprises outside the city is a very timeconsuming, costly, and lengthy process. Therefore, we consider it very important to create a comfortable living environment to carry out measures to improve heat and power plants and boiler houses toward their environmental safety.

Thus, we can say that the heat and power system has a huge impact on the comfort indicators of the 
residential environment and requires more detailed research and study in this context. Following this, it seems possible for us to investigate the influence factors of the centralized municipal heat supply system on the residential environment's comfort and build a methodology based on the Data Envelopment Analysis (DEA) method that will optimize this influence.

\section{Problem Formulation}

When functioning of different technical systems in a single space and interaction, their regulation arises while observing all the features of these systems. In our opinion, technical problems requiring solutions in interdisciplinary exchange are of high scientific interest because they need interaction from scientific groups of different subject areas. In this case, we consider it reasonably relevant and exciting to assess the functioning of the heat and power system under the prism of the comfort for the residential environment in the context of the housing and communal sector.

The constantly increasing costs of heating energy to compensate for the insufficient temperature inside residential complexes are one of the critical problems of housing construction in the northern regions. Therefore, one of the main criteria in the real estate market is the necessary level of heat comfort, achieved not only by the building's enclosing structures but also by the required power of the building's heating devices as a whole.

The concept of the living environment comfort includes a number of different factors and criteria with possible variations for each specific study area. We considered these factors in previous publications [4]. One of the factors influencing the perception of the living environment comfort is the microclimate inside residential buildings, which consistently includes a number of parameters that affect the person's perception of the live environment and the stability and resistance of the building structures in residential buildings. The parameters of the microclimate include heat comfort, humidity, insolation, as well as aeration. Accordingly, for regions with a particularly severe and cold climate, one of the most important parameters that are focused on when buying a residence is the heat comfort of residential buildings.

Many Russian and foreign studies have been devoted to solving this problem. In Russian research dedicated to heat comfort, several works can be distinguished devoted to determining the most comfortable parameters of heat comfort in a residential building for a person. In the work of Burlachenko N. L. [5], heat comfort is considered as one of the most important indicators of the living environment comfort. In the study of Gerasimov A. I. and Saltykov I. P. [6] an approach to assessing the level of internal conditions comfort in residential buildings created by "passive" or structural construction methods is considered. The work of Usmonov Sh. Z. [7] is interesting for a comprehensive analysis of the microclimatic parameters of a residential building to establish the maximum air temperature values in the buildings during the heating period. Finally, the study of M. V. Prorokova and V. V. Bukhmirov [8] reveals a new method for assessing the quality of the microclimate, which can be used in the design of heat grids.

Foreign researchers have attempted to optimize the cost of heat energy to create a comfortable indoor air temperature. A block of such works is represented by the study of Chen X., Wang Q., Srebric J. [9], Gallardo A., Palme M., Lobato-Cordero A., Beltrán R. D., Gaona G. [10], Genco A., Viggiano A., Viscido L., Sellitto G., Magi V. [11].

The block of studies of heat comfort as an integral part in the design of a modern residential building, as well as the energy efficiency of the building, is presented in the works of Hoof J., Mazej M., Hensen Jan L. M. [12], Kajtar L., Nyers J., Szabo J., Ketskemety L., Herczeg L., Leitner A., Bokor B. [13], as well as Olesen B. W. Seelen J [14], Nguyen A. T., Singh M. K., Reiter S. [15].

At the same time, the next important factor is the problem of ecology: low air quality requires the regulation of emissions of heat and power plants (HPP) and boiler houses, often located within the city boundaries. When fuel is burned, a massive amount of harmful emissions is released into the atmosphere. These include volatile organic compounds, solid ash particles, gaseous oxides of sulfur and nitrogen, volatile compounds of heavy metals. All this significantly worsens urban air quality, especially in residential areas located near such objects of the heat and power system.

The following works are devoted to solving the environmental problem in the heat and power system [16-18], etc. Furthermore, the following publications are dedicated to inventions and innovations that can improve heat and power plants in the direction of their environmental safety $[19,20]$, etc. In these works, new technologies for cleaning the fuel used by the HPP, the creation, production, and installation of special cleaning filters at the HPP, the construction of new heat and power plants designed initially considering modern environmental requirements are considered. The methods proposed above are quite expensive, therefore they do not help to completely solve the problem at the moment. 
An approach based on the DEA method to optimize the influence of the centralized municipal heat supply system on the comfort of the living environment has not been considered in the literature before.

In this study, it seems quite relevant to describe a methodology that will optimize the impact of the centralized municipal heat supply system on the comfort of the residential environment. This method will be based on the DEA method. This will allow us to select the leading performance indicators of urban heat and power plants (HPP) and boiler houses that affect the comfort of the living environment and optimize their indicators. Thus, the DEA method will help to adjust the performance of urban heat and power plants and boiler houses in such a way as to increase the comfort of the urban living environment. These aspects will be described in detail in the next section.

\section{Problem Solution}

So, in this section, we will describe a technique that will improve the comfort of the urban living environment. This method is based on the DEA method.

The method was first formulated by scientists Charnes, Cooper, and Rhodes in 1978. It was based on the method of mathematical programming and was widely developed in the following years. In the previous publication, we described the history of this method development and the main scientific works published [21].

The method was used in various fields to evaluate the effectiveness of the studied objects. For example, this method has been used to measure the efficiency of service enterprises [22], automobile industry [23], agricultural industry [24], ecology [25], information systems [26], transport [27], etc.

However, many authors give different definitions of this method. For example, according to [28], DEA is a linear programming quantitative method to evaluate production boundaries and evaluate the relative useful actions of identical production facilities, called decision-making units by scientists.

The DEA method is a fairly powerful comparative analysis tool that has found wide application to measure productivity in organizations [29]. In addition, DEA helps use multiple inputs and outputs in a linear software model [30].

It is also worth pointing out the main limitations of the DEA method, highlighted by scientists [31]:

- the method is not recommended to analyze small samples;
- the method measures relative efficiency, that is, it helps to compare objects only with each other;

- when calculating using the DEA method, noise or Outliers may appear.

DEA models are divided into input-oriented models and output-oriented models [3]

$\min _{\theta, \lambda, S^{-} . S^{+}}\left\{\theta-\varepsilon\left(\sum_{k=1}^{m} S_{k}^{-}+\sum_{i=1}^{r} S_{i}^{+}\right)\right\}$

Under the following specified constraints:

$\theta x_{k 0}-\sum_{j=1}^{n} x_{k j \lambda_{j}-S_{k}^{-}=0}, \mathrm{k}=1, \mathrm{~m}$,

$\sum_{j=1}^{n} x_{i j} \lambda_{j}-S_{i}^{+}=y_{i 0}, \mathrm{i}=1, \ldots \mathrm{r}$,

$\lambda_{j} \geq 0, \mathrm{j}=1, \ldots, \mathrm{n}$,

$S_{k}^{-} \geq 0, \mathrm{k}=1, \ldots, \mathrm{m}$,

$S_{i}^{+} \geq 0, \mathrm{i}=1, \ldots, \mathrm{r}$.

In order to avoid calculating the small parameter $\varepsilon$ Charnes, Cooper and Rhodes proposed to solve this problem in 2 stages [26].

First, the first problem of the form is solved:

$\min \theta$

under the following specified constraints:

$\theta x_{k 0}-\sum_{j=1}^{n} x_{k j \lambda_{j}-S_{k}^{-}=0}, \mathrm{k}=1, \mathrm{~m}$,

$\sum_{j=1}^{n} x_{i j} \lambda_{j}-S_{i}^{+}=y_{i 0}, \mathrm{i}=1, \ldots \mathrm{r}$,

$\lambda_{j} \geq 0, \mathrm{j}=1, \ldots, \mathrm{n}$,

$S_{k}^{-} \geq 0, \mathrm{k}=1, \ldots, \mathrm{m}$,

$S_{i}^{+} \geq 0, \mathrm{i}=1, \ldots, \mathrm{r}$.

Then the optimal value of the functional $\theta^{*}$ is fixed and the second problem is solved:

$\max \left(\sum_{k=1}^{m} S_{k}^{-}+\sum_{i=1}^{r} S_{i}^{+}\right)$

under the following specified constraints:

$\theta^{*} x_{k 0}-\sum_{j=1}^{n} x_{k j \lambda_{j}-S_{k}^{-}=0}, \mathrm{k}=1, \mathrm{~m}$,

$\sum_{j=1}^{n} y_{i j} \lambda_{j}-y_{i 0}-S_{i}^{+}=y_{i 0}, \mathrm{i}=1, \ldots \mathrm{r}$,

$\lambda_{j} \geq 0, \mathrm{j}=1, \ldots, \mathrm{n}$,

$S_{k}^{-} \geq 0, \mathrm{k}=1, \ldots, \mathrm{m}$,

$S_{i}^{+} \geq 0, \mathrm{i}=1, \ldots, \mathrm{r}$.

There is also an output model. This model has the following form [27]:

$\min _{\eta, \lambda, S^{-} . S^{+}} \eta$

under the following specified constraints:

$\sum_{j=1}^{n} x_{j} \lambda_{j}-S_{k}^{-}=x_{0}$

$\sum_{j=1}^{n} y_{j} \lambda_{j}-S_{i}^{+}=\eta y_{0}$

$\lambda_{j} \geq 0, \mathrm{j}=1, \ldots, \mathrm{n}$,

$S^{-} \geq 0$,

$S^{+} \geq 0$.

The DEA method helps to solve various problems of measuring the effectiveness of the studied objects. For example, in previous articles we evaluated the efficiency of the fuel and energy complex facilities, optimizing the technical indicators of the inputs and outputs of the studied enterprises. That is, the technical efficiency of the heat and power system as a whole was evaluated. In this study, we set a different task. And we will optimize the indicators of 
the heat and power system facilities to improve the comfort of the living environment. In accordance with this task, the DMU inputs and outputs will be determined. And also, a suitable DEA model has been determined to solve this problem.

Move on to the formation of indicators of inputs and outputs in accordance with the task being solved.

Above, we have described the main factors of the influence of the heat and power system on the comfort of the living environment. The main objects of the centralized municipal heat supply system that can have this effect are heat sources. In the urban environment, they are HPP and boiler houses. Most often, these are enterprises that require modernization, built more than 30 years ago. Therefore, the environmental factor described above is created by the sources of the centralized municipal heat supply system: HPP and boiler houses. It is impossible to move these objects of the heat and power system beyond the boundaries of the urban environment soon because this primarily requires significant financial investments.

For the same reason, it is impossible to carry out a rapid modernization of such facilities. Work in this direction is being carried out in many countries. But it is not yet possible to completely solve the problem since it takes time to implement measures in this direction systematically. At the same time, residential development is continuously carried out in the nearby areas from the location of HPP and boiler houses. And the population living in these areas is forced to get used to these unfavorable environmental conditions. Accordingly, the comfort of the living environment is significantly reduced for such areas, especially during heating periods. And in regions with a particularly severe and cold climate and high development of residential and industrial infrastructure, an environmental problem that worsens the comfort of the living environment becomes a problem not of individual districts but of the entire city. Therefore, we believe that it is quite relevant to optimize HPP and boiler houses' operation by minimizing the emission mass index for such facilities.

Consequently, we will reduce this indicator. The mass index of the emission (thousand tons per year) will be the output parameter. When using the DEA method, if it is necessary to minimize part of the output indicators, in our case - the mass of emissions from boiler houses, for calculations, not the actual values of the output indicators are used, but their deviations from the threshold value set at a level exceeding the values of these indicators for all the studied objects [32].
We described above that another critical factor that also affects the perception of the living environment comfort is the microclimate inside residential buildings, which includes several parameters that affect not only the perception of the living environment by a person but also the stability and resistance of the building structures in residential buildings. For regions with a particularly severe and cold climate, one of the most important parameters that are used when buying a house is the heat comfort of residential buildings. Analyze this issue from the point of view of optimizing this parameter by adjusting the performance indicators of HPP and boiler houses. Accordingly, it is possible to increase heat comfort due to the indicator of HPP plants and boiler houses: the release of heat energy to the grid. Furthermore, heat consumption by housing and communal services is constantly growing due to the appearance of new housing complexes and enterprises. Accordingly, the indicator of the release of heat energy to the grid tends to increase.

So, we have determined the output indicators for the DEA model.

Now move on to the input indicators. When setting the task of improving the comfort of the living environment, one input indicator is enough for us: the available capacity for the equipment of heat and power plants and boiler houses. Since they will not be able to produce more heat energy than their capacity can allow. Therefore, when setting up output indicators, it is necessary to consider this input indicator.

Thus, we have determined the input and output indicators for the DEA model. We have one input: the available heat power (Gcal / hour) and two outputs: the heat energy supply to the grid (thousand Gcal per year) and the mass of the emission (thousand tons per year). In this study, the above units of measurement are taken at the specified inputs and outputs. And, accordingly, the units of measurement will not be indicated in the tables of the above calculations for convenience and compactness of data presentation.

Now set a goal for the DEA model - to increase the output volume without increasing the input. So, with a certainly available heat capacity of HPP and boilers, which cannot be changed, we need to increase the amount of energy released to the grid, as well as reduce the number of emissions (in this case, as we described above, increase the deviation for the mass of emissions from the threshold value).

Accordingly, we will use the output-oriented DEA model for calculations.

According to the presented methodology, the results of calculations will contain indicators of 
optimal parameters for all values of the inputs and outputs of the system when solving the problem of improving the comfort of the living environment.

Now we are testing this technique on specific indicators of the inputs and outputs for objects. For example, take the indicators of HPP and boiler houses of the centralized municipal heat supply system in Krasnoyarsk, which belongs to a region with a particularly cold climate. In addition, it has a reasonably developed housing and industrial infrastructure and is one of the cities in Russia with an unfavorable environmental situation.

Based on the project "Heat and power scheme in the city of Krasnoyarsk until 2033", we will analyze this city's centralized municipal heat supply system; observations were conducted for two years. In the article, we will present only the primary data of the study. The main indicators of the inputs and outputs in the studied DMUs are given in table 1. In this table, the Emission mask indicator reflects the value considering deviations from the threshold value for the sample. The threshold value is 22 thousand tons per year.

Table 1. Source data - a list of DMUs, inputs, outputs.

\begin{tabular}{|c|c|}
\hline Inputs and outputs & Value \\
\hline \multicolumn{2}{|l|}{$\begin{array}{r}\text { DMU } 1 \\
\end{array}$} \\
\hline Available heat power & 1474 \\
\hline Heat energy supply to the grid & 3521 \\
\hline Emission mass & 814.3 \\
\hline \multicolumn{2}{|l|}{ DMU 2} \\
\hline Available heat power & 1305 \\
\hline Heat energy supply to the grid & 3450 \\
\hline Emission mass & 3761.7 \\
\hline \multicolumn{2}{|l|}{ DMU 3} \\
\hline Available heat power & 651.5 \\
\hline Heat energy supply to the grid & 1934 \\
\hline Emission mass & 9324 \\
\hline \multicolumn{2}{|l|}{ DMU 4} \\
\hline Available heat power & 279 \\
\hline Heat energy supply to the grid & 452.6 \\
\hline Emission mass & 21020.7 \\
\hline \multicolumn{2}{|l|}{ DMU 5} \\
\hline Available heat power & 156.4 \\
\hline Heat energy supply to the grid & 384.9 \\
\hline Emission mass & 19772.8 \\
\hline \multicolumn{2}{|l|}{ DMU 6 } \\
\hline Available heat power & 349.8 \\
\hline Heat energy supply to the grid & 785.6 \\
\hline Emission mass & 15548.4 \\
\hline \multicolumn{2}{|l|}{ DMU 7} \\
\hline Available heat power & 143.2 \\
\hline Heat energy supply to the grid & 443.4 \\
\hline
\end{tabular}

\begin{tabular}{|c|c|}
\hline Emission mass & 15220 \\
\hline \multicolumn{2}{|l|}{ DMU 8} \\
\hline Available heat power & 98.6 \\
\hline Heat energy supply to the grid & 87.8 \\
\hline Emission mass & 19769 \\
\hline \multicolumn{2}{|l|}{ DMU 9} \\
\hline Available heat power & 343 \\
\hline Heat energy supply to the grid & 453.4 \\
\hline Emission mass & 19289.4 \\
\hline \multicolumn{2}{|l|}{ DMU 10} \\
\hline Available heat power & 128 \\
\hline Heat energy supply to the grid & 177.6 \\
\hline Emission mass & 20215 \\
\hline \multicolumn{2}{|l|}{ DMU 11} \\
\hline Available heat power & 68.6 \\
\hline Heat energy supply to the grid & 78.4 \\
\hline Emission mass & 20758.5 \\
\hline \multicolumn{2}{|l|}{ DMU 12} \\
\hline Available heat power & 59.6 \\
\hline Heat energy supply to the grid & 89 \\
\hline Emission mass & 20170.4 \\
\hline \multicolumn{2}{|c|}{$\begin{array}{l}\text { Based on the presented data, we will determine } \\
\text { the scale effect for the output-oriented DEA model. } \\
\text { This study will use a variable return to scale [33] } \\
\text { since the data set is quite heterogeneous and has a } \\
\text { large spread. The coefficient of variation for } \\
\text { indicators of available heat capacity is } 117.67 \% \text {, for } \\
\text { indicators of heat energy supply to the grid is } \\
130.74 \% \text {, and for indicators of emission, mass is } \\
97.98 \% \text {. }\end{array}$} \\
\hline
\end{tabular}

To perform the calculations, we will use the Data Envelopment Analysis Program (DEAP) software of the University of New England in Australia, Professor T. Coelli [21].

For clarity and compactness of the presentation in calculated performance indicators by the DEA method, we group the effective DMUs into a separate table 2.

Table 2. Optimal DMU indicators when solving the problem of improving the comfort of the living environment. Effective objects.

\begin{tabular}{|l|c|c|}
\hline \multicolumn{1}{|c|}{ Inputs and outputs } & \multicolumn{2}{|c|}{ Value } \\
\cline { 2 - 3 } & $\begin{array}{c}\text { Differe } \\
\text { nce } \\
\text { between } \\
\text { values }\end{array}$ & $\begin{array}{c}\text { Differ } \\
\text { ence } \\
\text { in } \\
\text { \% }\end{array}$ \\
\hline \multicolumn{1}{|c|}{ DMU 1 } & \multicolumn{2}{|c|}{} \\
\hline Available heat power & 0 & $0 \%$ \\
\hline Heat energy supply to the grid & 0 & $0 \%$ \\
\hline Emission mass & 0 & $0 \%$ \\
\hline \multicolumn{1}{|c|}{ DMU 2 } & \multicolumn{2}{|c|}{} \\
\hline Available heat power & 0 & $0 \%$ \\
\hline Heat energy supply to the grid & 0 & $0 \%$ \\
\hline
\end{tabular}




\begin{tabular}{|c|c|c|}
\hline Emission mass & 0 & $0 \%$ \\
\hline DMU 3 & \multicolumn{2}{|c|}{1} \\
\hline Available heat power & 0 & $0 \%$ \\
\hline Heat energy supply to the grid & 0 & $0 \%$ \\
\hline Emission mass & 0 & $0 \%$ \\
\hline DMU 4 & \multicolumn{2}{|c|}{1} \\
\hline Available heat power & 0 & $0 \%$ \\
\hline Heat energy supply to the grid & 0 & $0 \%$ \\
\hline Emission mass & 0 & $0 \%$ \\
\hline DMU 5 & \multicolumn{2}{|c|}{1} \\
\hline Available heat power & 0 & $0 \%$ \\
\hline Heat energy supply to the grid & 0 & $0 \%$ \\
\hline Emission mass & 0 & $0 \%$ \\
\hline DMU 11 & \multicolumn{2}{|c|}{1} \\
\hline Available heat power & 0 & $0 \%$ \\
\hline Heat energy supply to the grid & 0 & $0 \%$ \\
\hline Emission mass & 0 & $0 \%$ \\
\hline DMU 12 & \multicolumn{2}{|c|}{$\mathbf{1}$} \\
\hline Available heat power & 0 & $0 \%$ \\
\hline Heat energy supply to the grid & 0 & $0 \%$ \\
\hline Emission mass & 0 & $0 \%$ \\
\hline
\end{tabular}

Now we will explain the results obtained, present recommendations, and conclude. So, table 2 shows all the calculated indicators and recommended values according to the methodology described in the study.

As shown in Table 2, the objects numbered 1-5, numbers 11,12 - the centralized municipal heat supply systems in the city of Krasnoyarsk function in an optimal mode relative to the studied taskimproving the comfort of the living environment. Therefore, their efficiency indicator relative to the impact on the comfort of the living environment is the maximum possible value and is equal to 1 . So, it is unnecessary to adjust the indicators of the inputs and outputs for seven objects of the centralized municipal heat supply system in Krasnoyarsk to improve the comfort of the living environment since they are already working in the optimal mode.

Next, we present table 3 with calculated performance indicators using the DEA method for inefficient DMUs (with an efficiency coefficient of less than 1).

Table 3. Optimal DMU indicators when solving the problem of improving the comfort of the living environment. Inefficient objects.

\begin{tabular}{|l|c|c|}
\hline \multirow{2}{*}{ Inputs and outputs } & \multicolumn{2}{|c|}{ Value } \\
\cline { 2 - 3 } & $\begin{array}{c}\text { Differe } \\
\text { nce } \\
\text { between } \\
\text { values }\end{array}$ & $\begin{array}{c}\text { Differ } \\
\text { ence } \\
\text { in } \\
\text { \% }\end{array}$ \\
\hline Object 6 & \multicolumn{2}{|c|}{$\mathbf{0 . 9 0 2}$} \\
\hline $\begin{array}{l}\text { Available heat power, Gcal / } \\
\text { hour }\end{array}$ & 0 & $0 \%$ \\
\hline
\end{tabular}

\begin{tabular}{|l|c|c|}
\hline $\begin{array}{l}\text { Heat energy supply to the } \\
\text { grid, thousand Gcal per year }\end{array}$ & 86.135 & $11 \%$ \\
\hline $\begin{array}{l}\text { Emission mass, thousand tons } \\
\text { per year }\end{array}$ & 1685.5 & $10.8 \%$ \\
\hline Object 7 & \multicolumn{2}{|c|}{$\mathbf{0 . 9 4 8}$} \\
\hline $\begin{array}{l}\text { Available heat power, Gcal / } \\
\text { hour }\end{array}$ & 0 & $0 \%$ \\
\hline $\begin{array}{l}\text { Heat energy supply to the } \\
\text { grid, thousand Gcal per year }\end{array}$ & 23.1 & $5.4 \%$ \\
\hline $\begin{array}{l}\text { Emission mass, thousand tons } \\
\text { per year }\end{array}$ & 4190.2 & $27.5 \%$ \\
\hline Object 8 & \multicolumn{2}{|c|}{$\mathbf{0 . 9 5 1}$} \\
\hline $\begin{array}{l}\text { Available heat power, Gcal / } \\
\text { hour }\end{array}$ & 0 & $0 \%$ \\
\hline $\begin{array}{l}\text { Heat energy supply to the } \\
\text { grid, thousand Gcal per year }\end{array}$ & 44.9 & $54.1 \%$ \\
\hline $\begin{array}{l}\text { Emission mass, thousand tons } \\
\text { per year }\end{array}$ & 1026.9 & $5.2 \%$ \\
\hline Object 9 & $\mathbf{2 0 . 9 2 5}$ \\
\hline $\begin{array}{l}\text { Available heat power, Gcal / } \\
\text { hour }\end{array}$ & -74.4 & $-20 \%$ \\
\hline $\begin{array}{l}\text { Heat energy supply to the } \\
\text { grid, thousand Gcal per year }\end{array}$ & 35.3 & $8.2 \%$ \\
\hline $\begin{array}{l}\text { Emission mass, thousand tons } \\
\text { per year }\end{array}$ & 1572 & $8.2 \%$ \\
\hline Object 10 & $\mathbf{0 , 9 7 2}$ \\
\hline $\begin{array}{l}\text { Available heat power, Gcal / } \\
\text { hour }\end{array}$ & 0 & $0 \%$ \\
\hline $\begin{array}{l}\text { Heat energy supply to the } \\
\text { grid, thousand Gcal per year }\end{array}$ & 8.4 & $5.4 \%$ \\
\hline $\begin{array}{l}\text { Emission mass, thousand tons } \\
\text { per year }\end{array}$ & 585.8 & $2.9 \%$ \\
\hline Now we wll expln the resuts & \\
\hline
\end{tabular}

Now we will explain the results obtained, present recommendations, and conclude. So, table 3 shows all the calculated indicators and recommended values according to the methodology described in the study.

But as we can see from Table 3, the remaining five objects of the city's centralized municipal heat supply system have an efficiency indicator relative to the impact on the comfort of the living environment less than 1 .

Accordingly, these objects have inputs and outputs from the recommended optimal values for solving this problem. So, for five objects with a coefficient of less than 1 , it is required to configure the input and output indicators to work in the optimal mode to increase the comfort of the living environment in Krasnoyarsk.

Look at these objects in more detail.

For object number 6 , with the existing maximum available capacity, it is required to increase the supply of thermal energy to the grid by $11 \%$. At the same time, the mass of the ejection must be reduced by $10.8 \%$. 
For object number 7 , with the existing maximum available capacity, it is required to increase the supply of thermal energy to the grid by $5.4 \%$. At the same time, the mass of the ejection must be reduced by $27.5 \%$.

For object number 8 , it is recommended, with the existing maximum available capacity, to increase the supply of thermal energy to the grid by $54.1 \%$. At the same time, the mass of the ejection must be reduced by $5.2 \%$. For object number 9 , it is required to increase the supply of thermal energy to the grid by $8.2 \%$ while reducing the existing available capacity by $20 \%$. At the same time, the mass of the ejection must be reduced by $8.2 \%$.

For object number 10, with the existing maximum available capacity, it is required to increase the supply of thermal energy to the grid by $5.4 \%$. At the same time, the mass of the ejection must be reduced by $2.9 \%$.

Thus, with this set of the recommended values of the input and output parameters, it is possible to optimize the operation for objects of the centralized municipal heat supply system to increase the comfort of the residential environment in the city of Krasnoyarsk without significant financial investments.

\section{Conclusion}

In this article, the factors of the influence of the heat and power system on the comfort of the residential environment were studied. A technique was described that helps to optimize the influence of the centralized municipal heat supply system on the comfort of the living environment. The peculiarity of modern heat supply is its high social role - ensuring the vital activity of the population in the country. Therefore, for the Nordic countries, high-quality heating of territories becomes a very important social task and has a high impact on the comfort of the living environment. This article was devoted to solving this problem.

The presented methodology is based on the DEA method. In the article, we presented a description of the method and considered the basic model used in the study. The DEA method makes it possible to select the main performance indicators of urban heat and power plants and boiler houses that affect the comfort of the living environment and optimize them. This method helps to adjust the performance of urban heat and power plants and boiler houses in such a way as to increase the comfort of the urban living environment. This technique has not been previously considered in world scientific literature.

The presented methodology was tested on specific performance indicators of heat and power plant facilities and boiler houses of the centralized municipal heat supply system in Krasnoyarsk. It belongs to a region with a particularly cold climate. Nevertheless, it has a reasonably developed housing and industrial infrastructure, being one of the cities of Russia with an unfavorable environmental situation.

For the calculations carried out in the study, data from the document "Heat and power scheme in the city of Krasnoyarsk until 2033" were used. Based on which the objects of the centralized municipal heat supply system of the city were analyzed. The observations were conducted over two years. Therefore, the article presents only the main results of the study. The Data Envelope Analysis Program (DEAP) software in the University of New England in Australia, Professor T. Coelli, was used to perform the calculations.

We analyzed twelve objects of Krasnoyarsk's centralized municipal heat supply system from among boiler houses and heat and power plants. A calculation was made to optimize the performance of these facilities to improve the comfort of the living environment in Krasnoyarsk. Seven objects of the system work in an optimal mode. So, it is unnecessary to adjust the indicators of the inputs and outputs for seven objects of the city's centralized municipal heat supply system to improve the comfort of the living environment since they are already working in an optimal mode.

Five objects of the centralized municipal heat supply system in Krasnoyarsk have an efficiency indicator relative to the solved task of improving the comfort of the living environment less than 1 .

Accordingly, these objects have inputs and outputs from the recommended optimal values for solving this problem. So, for five objects with a coefficient of less than 1 , it is required to configure the inputs and outputs to work in an optimal mode to increase the comfort of the living environment in Krasnoyarsk.

Thus, for object number 6 , with the existing maximum available capacity, it is required to increase the supply of thermal energy to the grid by $11 \%$. At the same time, the mass of the ejection must be reduced by $10.8 \%$.

For object number 7 , with the existing maximum available capacity, it is required to increase the supply of thermal energy to the grid by $5.4 \%$. At the same time, the mass of the ejection must be reduced by $27.5 \%$.

For object number 8 , it is recommended, with the existing maximum available capacity, to increase the supply of thermal energy to the grid by $54.1 \%$. At the same time, the mass of the ejection must be reduced by $5.2 \%$. 
For object number 9 , it is required to increase the supply of thermal energy to the grid by $8.2 \%$ while reducing the existing available capacity by $20 \%$. At the same time, I need to reduce the mass of the ejection by $8.2 \%$.

For object number 10, with the existing maximum available capacity, it is required to increase the supply of thermal energy to the grid by $5.4 \%$. At the same time, the mass of the ejection must be reduced by $2.9 \%$.

Thus, with this set of the recommended values of the input and output parameters, it is possible to optimize the operation of objects of the centralized municipal heat supply system to increase the comfort index of the residential environment in the city of Krasnoyarsk without significant financial investments. That will contribute to improving the environmental situation in the city, especially in residential areas. This technique was applied to optimize the influence of the centralized municipal heat supply system on the comfort of the residential environment in the city of Krasnoyarsk and can be further used to solve such problems. The study has not been tested at facilities in other territories. But it is assumed that this technique can be applied to other regions with a particularly severe and cold climate. The results of this study will be applied to the development of an automated geoinformation system, as well as an expert system of residential complexes in the city of Krasnoyarsk.

\section{References:}

[1] E. G. Gasho, V. S. Puzakov, S. V. Guzhov Analysis of problems and trends in the development of heat and power system $\mathrm{s}$ in large cities of Russia. Heatenegetics, 2021, 3: 75-88

[2] A. A. Karabekova Development of heat electric power industry: analysis, problems, prospects. Proceedings of the St. Petersburg State University of Economics, 2017, 3 (105):123-127.

[3] B. L. Paskar Operation of heat and power plants and systems. Written lectures. - St. Petersburg, 2004. - $36 \mathrm{p}$.

[4] A. Stupina, O. Shagaeva, S. Yamaletdinov, O. Antamoshkin, R. Kuzmich1, I. Ruiga1 (2021) A New System for Evaluating a Siberian City: Evaluation Methodology. Civil Engineering and Architecture 9(5): 1318-1326, 2021.

[5] N. L. Burlachenko The concept of living environment comfort in modern conditions. Construction and architecture - 2015. - p. 47-49.

[6] Gerasimov A. I., Saltykov I. P. Approach to the assessing the comfort of the internal living environment in the premises of residential buildings by construction methods. Bulletin of the MGSU. 2011. No. 2. pp. 406-411

[7] Usmonov Sh.Z. Simulation of Energy Demand for Heating and Cooling of a 5-Storey Residential Building and Evaluation of Heat Conditions Based on PMV and PPD Heat Comfort Indices. Proceedings of Moscow State University of Civil Engineering. 2013, 10: 216-229.

[8] M. V. Prorokova., V. V. Bukhmirov. Energy saving and microclimate quality. Bulletin of the Cherepovets State University-2015. - p. 32-35

[9] Chen X., Wang Q., Srebric J. Model predictive control for indoor heat comfort and energy optimization using occupant feedback. Energy and Buildings. 2015, 102: 357-369.

[10] Gallardo A., Palme M., Lobato-Cordero A., Beltrán R. D., Gaona G. Evaluating Heat comfort in a Naturally Conditioned Office in a Temperate Climate Zone. Buildings. 2016, 6 (3): 27;

[11] Genco A., Viggiano A., Viscido L., Sellitto G., Magi V. Optimization of microclimate control systems for air-conditioned environments. International journal of heat and technology. 2017, 35 (1): S236-S243.

[12] Hoof1 J., Mazej M., Hensen Jan L. M. Heat comfort: research and practice. Frontiers in Bioscience. 2010, 15:765-788.

[13] Kajtar L., Nyers J., Szabo J., Ketskemety L., Herczeg L., Leitner A., Bokor B. Objective and Subjective Heat Comfort Evaluation in Hungary. Heat Science. 2017, 21 (3): 1409-1418.

[14] Olesen B. W. Seelen J. Criteria for a comfortable indoor environment in buildings. Journal Heat Biology. 18 (5-6): 545-549

[15] Nguyen A. T., Singh M. K., Reiter S. An Adaptive Heat Comfort Model for Hot Humid South. Building and Environment. 2012, 56: 291-300.

[16] K. V. Strelkova Problems of ensuring environmental safety of heat grid. E-SCIO. 2021, 7 (58): 90-97.

[17] Gagarin V. G. Macroeconomic aspects of the justification of energy-saving measures for increasing the heat protection of building enclosing structures. Construction Materials. 2010: 8-13.

[18] S. K. Sahoo, G. Sharma, A. Panwar, and R. C. Bansal Frequency regulation of wind integrated power system using dualmode fuzzy, Energy Procedia, 2019, 158: 6321-6327.

[19] A. Agazzani, A. F. Massardo, C. A. Frangopoulos Environmental Influence on the Thermoeconomic Optimization of a Combined Plant with NOx Abatement. J. Eng. Gas Turbines Power. 1998, 120(3): 557-565.

[20] Amir A. Safa, Alan S. Fung, Rakesh Kumar 
Performance of two-stage variable capacity air source heat pump: Field performance results and TRNSYS simulation. Energy and Buildings. 2015, 94: 80-90.

[21] M. Pokushko, A. Stupina, I. Medina-Bulo, E. Dresvianskii, A. Stupin, R. Kuzmich, I. Ruiga, L. Korpacheva (2021) Evaluating the Efficiency of Heat and Power Systems by the Data Envelopment Analysis Method. WSEAS Transactions on Power Systems, 16.

[22] Sherman, H. D., \& Zhu, J. (2006). Service productivity management: Improving service

performance using data envelopment analysis (DEA). New York: Springer.

[23] Tran, D. H., \& Ngo, D. T. (2014, June). Performance of Vietnamese automobile industry; A measurement using DEA. Asian Journal of Business and Management, 2(3), 184-191.

[24] Halická M, Trnovská M (2018) Negative features of hyperbolic and directional distance models for technologies with undesirable outputs. Cent Eur J Oper Res.

[25] Foroughi AA, Shureshjani RA (2017) Solving generalized fuzzy data envelopment analysis model: a parametric approach. Cent Eur J Oper Res 25(4):889-905.

[26] Takano Y, Ishii N, Muraki M (2017) Multiperiod resource allocation for estimating project costs in competitive bidding. Cent Eur J Oper Res 25(2):303.

[27] Matulová M, Fitzová H (2018) Transformation of urban public transport financing and its effect on operators' efficiency: evidence from the Czech Republic. Cent Eur J Oper Res.

[28] Shao Y, Bi G, Yang F, Xia Q (2018) Resource allocation for branch grid system with considering heterogeneity based on DEA method. Cent Eur J Oper Res.

[29] Toloo M, Tavana M, Santos-Arteaga FJ (2017) An integrated data envelopment analysis and mixed integer non-linear programming model for linearizing the common set of weights. Cent Eur J Oper Res.

[30] Fu, J (2018) Two-stage data envelopment analysis with undesirable intermediate measures: an application to air quality improvement in China. Cent Eur J Oper Res.

[31] Ramanathan, R. (2003). An introduction to data envelopment analysis: A tool for performance measurement. Thousand Oaks (Calif.): Sage.

[32] Emrouznejad, A., Parker, B. R., \& Tavares, G. (2008). Evaluation of research in efficiency and productivity: A survey and analysis of the first 30 years of scholarly literature in DEA. Socio-Economic Planning Sciences, 42(3), 151-157.
[33] Lei, X., Li, Y., Xie, Q., \& Liang, L. (2014). Measuring Olympics achievements based on a parallel DEA approach. Annals of Operations Research 226(1), 379-396.

\section{Contribution of individual authors to the creation of a scientific article (ghostwriting policy)}

Mariia Pokushko, Alena Stupina, Inmakulada Medina-Bulo conducted a simulation of the methodology for optimizing the centralized municipal heat supply system using the DEA method to improve the comfort of the residential environment, organized experiments in section 3 , and prepared a publication.

Olga Shagaeva and Egor Dresvianskii were engaged in the formulation of research goals and objectives, organized the resource provision of information and reference materials for research, were engaged in the preparation and editing of the publication.

Oleslav Antamoshkin, Roman Kuzmich, Mariia Tsepkova were responsible for statistics, were engaged in data storage and processing, carried out data analysis, processing and visualization. They engaged in the design of the publication.

\section{Sources of funding for research presented in a scientific article or scientific article itself}

The presented research was funded by Krasnoyarsk Regional Fund of Science in the framework of the scientific project "Modeling of the architectural structure and development of qualitative characteristics of the residential environment of Krasnoyarsk" (KF-773).

\section{Creative Commons Attribution}

\section{License 4.0 (Attribution 4.0 \\ International, CC BY 4.0)}

This article is published under the terms of the Creative Commons Attribution License 4.0 https://creativecommons.org/licenses/by/4.0/deed.en _US 